Tese apresentada ao Programa de Pós-graduaÇão em Psicologia da PUC-Rio COMO REQUISITO PARCIAL PARA OBTENÇÃO DO TÍTULO DE DOUTOR EM PSICOLOGIA. APROVADA PELA COMISSÃO EXAMINADORA ABAIXO ASSINADA.

Orientador: Prof. Dr. MARCus ANDrÉ VIEIRA

RIO DE JANEIRO, 29 DE MARÇO DE 2010 
Maritza de Magalhães Garcia

\section{Da metáfora ao literal - Jacques Lacan com Arnaldo Antunes}

Tese apresentada como requisito parcial para obtenção do grau de Doutor pelo Programa de Pós-Graduação em Psicologia Clínica do Departamento de Psicologia do Centro de Teologia e Ciências Humanas da PUC-Rio. Aprovada pela Comissão Examinadora abaixo assinada.

Prof. Marcus Andre Vieira

Orientador

Departamento de Psicologia - PUC-Rio

Profa. Ana Maria Rudge

Departamento de Psicologia - PUC-Rio

Profa. Ana Lucia Lutterbach Holck Instituto de Clínica Psicanalítica - ICP

Profa. Angélica Bastos de Freitas Rachid Grimberg UFRJ

Prof. Sergio Augusto Chagas de Laia Universidade FUMEC - MG

Prof. Paulo Fernando Carneiro de Andrade Coordenador Setorial de Pós-Graduação e Pesquisa do Centro de Teologia e Ciências Humanas - PUC-Rio

Rio de Janeiro, / / /2010. 
Todos os direitos reservados. É proibida a reprodução total ou parcial do trabalho sem autorização da universidade, da autora e do orientador.

\section{Maritza de Magalhães Garcia}

Graduou-se em Psicologia na Universidade Santa Úrsula em 1998. Concluiu a Especialização em Atendimento Psicanalítico em Instituição no IPUB - Instituto de Psiquiatria da Universidade Federal do Rio de Janeiro em 2001. Defendeu dissertação de mestrado na UERJ Universidade Federal do Estado do Rio de Janeiro em 2003. É diretora do Instituto OCA, onde coordena projetos sócio-culturais, além de realizar e supervisionar atendimentos psicanalíticos e oficinas de escrita com crianças e adolescentes.

Ficha Catalográfica

Garcia, Maritza de Magalhães

Da metáfora ao literal Jacques Lacan com Arnaldo Antunes / Maritza de Magalhães Garcia; orientador: Marcus André Vieira. - 2010.

191 f. : il. (color.) ; $30 \mathrm{~cm}$

Tese (Doutorado em Psicologia)-Pontifícia Universidade Católica do Rio de Janeiro, Rio de Janeiro, 2010.

Inclui bibliografia

1. Psicologia - Teses. 2. Psicanálise. 3. Significante. 4. Metáfora. 5. Psicose. 6. Letra. 7. Antunes, Arnaldo. I.Vieira, Marcus André. II.Pontifícia Universidade Católica do Rio de Janeiro. Departamento de Psicologia. III. Título.

CDD: 150 


\section{Agradecimentos}

Ao meu orientador, Marcus André Vieira, pela constante aposta.

À CAPES e à PUC-Rio, pelos auxílios concedidos como incentivo à produção, sem os quais este trabalho não poderia ter sido realizado.

A todos os professores e funcionários do Departamento do Departamento de Psicologia da PUC-Rio.

Aos professores que participaram da Comissão Examinadora.

À minha mãe, Eleusa, pela compreensão de sempre.

À meu pai, José, in memoriam, especialmente por ter me contado um pouco sobre seus sonhos em uma época em que eu nem sonhava que o inconsciente pudesse existir, insistir ou ex-sistir.

Ao meu marido, Alain, por me acompanhar poética e musicalmente na vida.

À Vanessa, minha filha, por ter me ensinado, entre muitas outras coisas, sobre o intenso movimento de construção de suas primeiras palavras, como boi-abada (goiabada) e pom (pão), que hoje fazem parte do seu dia-a-dia de chef de cozinha (não sei se é bem assim que se escrevem essas palavras, então as transcrevi transcriando).

Às engenhosas aventuras de Arnaldo Antunes com as palavras, bem como às dos fundadores da poesia concreta: Augusto de Campos, Haroldo de Campos e Décio Pignatari.

À Graça Pamplona, pela grande amizade, pela atenção, pelo debate de questões e pelo carinho e confiança ao me emprestar sua casa no alto da serra petropolitana, onde encontrei a concentração necessária ao fluxo da escrita.

Aos participantes da oficina de escrita que realizo no Instituto OCA, que, no trabalho com a palavra falada e escrita, se dispuseram ao encontro com o texto de Arnaldo Antunes.

A Guilherme Gutman e à Noemi Coelho pela lembrança carinhosa no envio de revistas e reportagens sobre Arnaldo Antunes.

A Manoel Motta, pela conversa sobre poesia concreta. 
À Tatiane Grova, pela preciosa ajuda na formatação das referências bibliográficas.

Aos meus amigos e familiares queridos, Marina Lutfi, Amapola Rios, Rodrigo Bleque, Jarbas e Isabel Ribeiro, Maria Cristina Mendes, Alessandra Machado, Daniela Camargo, João Pamplona, Homerinho e Rosângela, Clarice Gatto, Rafael Machado, Marcelo Rodolfo e Regina Cunha, sempre a postos. 


\section{Resumo}

Garcia, Maritza de Magalhães; Vieira, Marcus André. Da metáfora ao literal - Jacques Lacan com Arnaldo Antunes. Rio de Janeiro, 2010. 191p. Tese de Doutorado - Departamento de Psicologia, Pontifícia Universidade Católica do Rio de Janeiro.

Este trabalho privilegia um trajeto no ensino de Jacques Lacan que vai de sua peculiar apropriação do conceito lingüístico de significante, incluindo suas bases teóricas em Sigmund Freud, até sua teorização de lalíngua, que delimita o inconsciente formulado como um saber que ultrapassa o que se pode chamar de linguagem. Trata-se de um saber-fazer com restos de palavras que constitui a própria matéria de que o inconsciente é feito. Esse percurso segue elementos determinados da teoria lacaniana: a estruturação do inconsciente como uma linguagem, os mecanismos de constituição da metáfora e a concepção de letra, indo da palavra metafórica, que circula como bem ou mal-entendido, ao seu osso, à letra que constitui a matéria corporal que resta da palavra. A psicose é abordada tanto como o lugar onde a metáfora é construída por uma via diferente da que produz a significação corrente, quanto na vertente das singulares invenções no trabalho com a letra. A poesia de Arnaldo Antunes mapeia o percurso apresentando um modo de construção com a materialidade da palavra que nos ensina sobre a psicose, bem como sobre o trabalho do psicanalista com a fala.

\section{Palavras-chave}

Psicanálise, significante, metáfora, psicose, letra, Arnaldo Antunes. 


\section{Résumé}

Garcia, Maritza de Magalhães; Vieira, Marcus André. De la métaphore au literal - Jacques Lacan avec Arnaldo Antunes. Rio de Janeiro, 2010. 191p. These de Doctorat. Departement de Psychologie, Pontifícia Universidade Católica de Rio de Janeiro.

Cette recherche entend privilégier un trajet dans l'enseignement de Jacques Lacan en partant de l'appropriation particulière du concept linguistique de signifiant, incluant les bases théoriques de Sigmund Freud, jusqu'à sa théorisation de lalangue, qui délimite l'inconscient formulé comme un savoir qui dépasse ce que l'on peut appeler de langage. Il s'agit d'un savoir-faire avec des restes de mots qui constitue la matière même dont l'inconscient est fait. Ce parcours suit des éléments établis de la théorie lacanienne : la structuration comme un langage, les mécanismes de constitution de la métaphore et la conception de lettre, allant du mot métaphorique qui circule comme bien ou mal entendu, à son ossature, à la lettre qui constitue la matière de la parole. La psychose est abordée aussi bien comme le lieu où la métaphore est construite par une voie différente de celle qui produit la signification courante, que par le cheminement des singulières inventions dans le travail avec la lettre. La poésie d'Arnaldo Antunes cartographie ce parcours en présentant un mode de construction avec la matérialité du mot qui nous apporte un enseignement sur la psychose, ainsi que sur le travail du psychanalyste avec la parole.

\section{Mots-clefs}

Psychanalise, signifiant, metaphore, psychose, lettre, Arnaldo Antunes 


\section{Sumário}

1. Introdução 12

2. A ressonância da palavra é constitucional 16

2.1. Freud e Brentano - Introdução do conceito de representação 17

2.2. A representação e as afasias 18

2.2.1. Um certo aparelho de linguagem e a Klangbilder como uma 20 formação primeira da palavra no inconsciente

2.2.2. Os traços na Carta 52, entre O Projeto e a Interpretação dos 21 Sonhos

2.3. O Vorstellungrepräsentanz é o traço unário 23

2.4. Os trilhos do simbólico de Lacan 25

2.4.1. A significação resiste $\quad 29$

2.5. A verdade é a poesia 31

2.6. O Bloco Mágico de Freud - a inscrição de uma ausência não- 33 simbolizável

2.7. Um efeito de sentido, a marca da divisão do sujeito, o nãosimbolizável e a metáfora girando em torno de um nome: O Nome-doPai

2.8. O ouro da palavra, um acidente. O Witz na psicanálise

2.9. Verdichtung, metáfora e poesia - a essência poética do inconsciente

2.10. Booz Endormi, o feixe e a metáfora 48

2.11. A metonímia 53

2.12. O desejo e a Spaltung $\quad 57$

3. As ressonâncias da voz na psicose $\quad 59$

3.1. Schreber é um escritor, não um poeta 60 
3.2.1. Unglauben, Bejahung e Verneinung 64

3.2.2. A Verwerfung $\quad 67$

3.2.3. Ideal e metáfora delirante 69

3.3. A voz da alucinação, o ouro da palavra na psicose - o encontro da 72 voz do Outro entre o imaginário e o real

3.3.1. O eco do Narcisismo 73

3.3.2. Alucinação e eco 76

$\begin{array}{ll}\text { 3.4. A pulsão de voz } & 77\end{array}$

3.5. O corpo da palavra $\quad 80$

3.6. A voz como objeto $a$

$\begin{array}{lr}\text { 3.7. O gozo } & 87\end{array}$

3.8. Duas situações clínicas que falam da voz e do gozo como ossos do 91 significante

3.9. Lalíngua, uma invenção que marca um novo modo de fazer poesia? 93

4. A letra entre Arnaldo Antunes e Jacques Lacan 97

4.1. Porque Arnaldo Antunes? $\quad 98$

4.2. Antunes no cenário artístico brasileiro 99

4.3. Matéria-prima de Antunes 104

4.4. Caligrafias 109

4.5. Poesia Concreta 113

4.6. Haroldo de Campos e a psicanálise 115

4.7. Rumos da letra 118

4.8. A estrutura fonemática do significante $\quad 120$ 
4.10. A letra como traço e uma visada de Derrida

4.11. Entre o escrito e a fala, uma montanha

4.12. O irredutível da escrita

4.13. Lituraterra, uma nova rota para a letra

4.14. Da letra como escrita de gozo ao gozo como prazer da linguagem

4.15. Do pai como letra ao real da mãe, o horizonte de lalíngua

5. Conclusão

6. Anexo - Coletânea de referências de Lacan sobre a poesia

7. Referências Bibliográficas 


\section{Lista de figuras}

Figura 1 - Esquema da memória em Freud 22

$\begin{array}{ll}\text { Figura } 2 \text { - Esquema de Saussure } & 27\end{array}$

Figura 3 - Primeira fórmula da metáfora em Lacan 36

Figura 4 - Segunda fórmula da metáfora em Lacan 37

Figura 5 - Soneto. Antunes, 1996.

Figura 6 - A estrutura do chiste em Freud 43

Figura 7 - H2O mem. Antunes, 2001. 80

Figura 8 - Colagem fotográfica. Antunes, 2006, p.301. 108

Figura 9 - Aqui aquilo. Antunes, 1998.

Figura 10 - agá. Antunes, $1997 . \quad 118$

$\begin{array}{ll}\text { Figura } 11 \text { - dáctilo e anapesto. } & 128\end{array}$

Figura 12 - the and. Antunes, 2003. 